\title{
Identification of two divergent swine Noroviruses detected at the slaughterhouse in North East Italy
}

\author{
Andrea Laconi ${ }^{1,2^{*}+}$, Lara Cavicchio ${ }^{3 \dagger}$, Luca Tassoni ${ }^{3}$, Giovanni Cunial ${ }^{4}$, Adelaide Milani ${ }^{1}$, Martina Ustulin ${ }^{5}$, \\ Guido Di Martino ${ }^{4}$, Mario Forzan ${ }^{6}$, Mery Campalto ${ }^{3}$, Isabella Monne ${ }^{1}$ and Maria Serena Beato ${ }^{3}$
}

\begin{abstract}
Norovirus (NoV) has emerged as one of the major causative agents of non-bacterial, food- and water-borne gastroenteritis in humans, with the main genogroup involved in human outbreaks (GII), which has been detected worldwide in different animal species including swine. A four-month investigation at the slaughterhouse aiming to examine the presence of NoV in the swine in North-Eastern Italy, enabled the detection of two divergent Noroviruses (NoVs) (GII.P11) in two swine farms. This represents the first study in the swine population of North-Eastern Italy, which has paved the way for future integrated virological and epidemiological investigations on swine Novs.
\end{abstract}

Keywords: Norovirus, Swine, Survey, Recombination, Slaughterhouse

\section{Background}

Noroviruses (NoVs) are a leading pathogen of foodborne diseases, which cause an estimated 23 million cases of illness annually in the USA, and $>90 \%$ of nonbacterial epidemic gastroenteritis cases worldwide [1, 2]. NoVs are transmitted through the ingestion of contaminated food or water, either via the faecal-oral route or via air-borne particles and contact with contaminated surfaces [3]. NoVs belonging to the Caliciviridae family are classified into ten genogroups (GI-GX), based on the variation of the major capsid protein (VP1), and are further divided into 49 genotypes [4]. The genetic diversity of the RNA-dependent-RNA-polymerase (RdRp) dictates the number of p-types [4]. NoVs detected in naturally infected pigs are classified as GII, which can also infect humans [5-9]. Since the first report of GII NoVs in pigs

\footnotetext{
*Correspondence: andrea.laconi@unipd.it

${ }^{\dagger}$ Andrea Laconi and Lara Cavicchio contributed equally to this work.

${ }^{1}$ Research and Development Laboratory, Istituto Zooprofilattico Sperimentale Delle Venezie, Legnaro, Padua, Italy

${ }^{2}$ Department of Comparative Biomedicine and Food Science, University of Padua, Legnaro, Padua, Italy

Full list of author information is available at the end of the article
}

in the USA [10], other countries have reported the presence of this genogroup in diseased and healthy pigs [11]. However, little is known about the GII distribution and the epidemiological characteristics of NoVs in swine. Currently, no data are available on the NoVs prevalence in swine in Italy, although, belonging to the family Caliciviridae, they are listed among zoonotic agents that European member states should report on [12-15]. The aim of this study was to investigate the presence of NoVs in swine in two North East Italian regions, Veneto and Friuli Venezia Giulia (FVG).

\section{Materials and methods}

Seventy-nine faecal samples from 76 swineherds were collected at three slaughterhouses between March and June 2017. Forty swine herds were distributed in Veneto (eighteen fattening, six farrow to wean and sixteen farrow to finish) and 36 in FVG (thirty fattening farms, one farrow to wean and five farrow to finish).

Faecal samples were diluted 1:5 (weight $(\mathrm{w}) /$ volume (v)) in Phosphate Buffered Saline (PBS) supplemented with antibiotics $(10,000 \mathrm{IU} / \mathrm{ml}$ of penicillin $\mathrm{G}, 10 \mathrm{mg} / \mathrm{ml}$ 
of streptomycin, $5000 \mathrm{IU} / \mathrm{ml}$ nystatin, $0.25 \mathrm{mg} / \mathrm{ml}$ gentamicin sulphate) (Sigma Aldrich, St. Louis, Missouri, USA). The homogenates were diluted in a final $20 \%$ glycerol solution (v/v) (Sigma Aldrich, St. Louis, Missouri, USA), vortexed and centrifuged, and the supernatants collected, aliquoted and stored at $-80^{\circ} \mathrm{C}$. Viral RNA was isolated using QIAamp Viral RNA mini kit (QIAGEN, Hilden, Germany).

One-step RT-PCRs were performed using the SuperScript III One-Step RT-PCR System with Platinum Taq DNA polymerase kit (Invitrogen, Carlsbad, CA, USA). For NoV detection an approach based on a universal one-step RT-PCR for Caliciviridae family $[10,16]$ targeting a 300 bp RdRp fragment, paired with Sanger sequencing and BLAST search was adopted. Primers pair NVG4F and VN3T20 [10] were used to amplify a genomic portion of about $2500 \mathrm{bp}$ containing the VP1 coding region, followed by sanger sequencing and BLAST search. A primer-walking approach based on newly designed primers (Table 1) was used to amplify and sequence $\mathrm{NoV}$ full genome applying the thermal cycling profile reported in Table 2.

Nucleotide (nt) sequences of the partial RdRp and of the VP1 were aligned with the MAFFT online software version 7 (https://mafft.cbrc.jp/alignment/software/). The best substitution model was identified using MEGA 6.0 and the phylogenetic analysis was performed with PhyML 3.0 with 100 replicate of bootstrap.

The presence of recombination events was investigated using RDP4 software (http://web.cbio.uct.ac.za/ darren/
Table 2 Thermal cycling profile used for one-step RT-PCRs developed in the present study as part of the in-house primerwalking approach to amplify the whole genome sequence of swine NoVs

\begin{tabular}{llll}
\hline Thermal cycling profile & Temperature & Duration & $\mathrm{N}^{\circ}$ cycles \\
\hline Reverse transcription reaction & $50^{\circ} \mathrm{C}$ & $60 \mathrm{~min}$ & \\
Polymerase Activation & $94^{\circ} \mathrm{C}$ & $2 \mathrm{~min}$ & \\
Denaturation & $94^{\circ} \mathrm{C}$ & $15 \mathrm{~s}$ & $\times 40$ \\
Annealing & $50 \sim 60^{\circ} \mathrm{C}$ & $30 \mathrm{~s}$ & \\
Elongation & $68^{\circ} \mathrm{C}$ & $1 \sim 2 \mathrm{~min}$ & \\
Final elongation & $68^{\circ} \mathrm{C}$ & $5 \mathrm{~min}$ & \\
\hline
\end{tabular}

rdp.html) using eight methods (RDP, GENECONV, BOOTSCAN, MAXCHI, CHIMAERA, SISCAN, PHYLPRO and 3SEQ) and ten representative NoV full genome $\begin{array}{llll}\text { sequences } & \text { (JX023285.1 } & \text { GI.1; } & \text { X81879.1 GII.2; }\end{array}$ AB039781.1 GII.3; AB220921.1 GII.4; AY502023.1 GII.4; AB039779.1 GII.6; HQ169542.2 GII.6; HQ392821.1 GII.11; AY772730.1 GII.16; AY823305.2 GII.18).

\section{Results and discussion}

Two out of seventy-nine faecal samples (2.53\%) resulted NoV positive and characterized as GII.P11 based on the RdRp sequence (Fig. 1). NoVs were identified in two different fattening farms located in Veneto provinces in March and June 2017, namely: NoV/Italy/swine/ 17DIAPD90019/2017 (90019/2017) from Padova province and NoV/Italy/swine/17DIAPD90078/2017 (90078/

Table 1 Primers used for reverse transcription, PCR and sequencing. Primer names generally indicate approximate binding positions in the NoVs genome

\begin{tabular}{|c|c|c|c|}
\hline Primer & Sequence $\left(5^{\prime}-3^{\prime}\right)$ & Genome Position (nt) & Amplicon size \\
\hline NORP7F & GAAGATGGCGTCTAACGACG & $7-27$ & $539 \mathrm{bp}$ \\
\hline NORP_546R & TGAGGGACATGCACCACTC & $527-546$ & \\
\hline NORP_374F & GAACCACTCCCAGGCTCTAT & $374-394$ & $876 \mathrm{bp}$ \\
\hline NORP_1250R & CCTCCATGTCTAGAACAGCA & $1230-1250$ & \\
\hline NORP1085F & CGCATGTTCACTTCAGCAGC & $1085-1105$ & $951 \mathrm{bp}$ \\
\hline NORP2036R & CCCTTYCCATAAGGGGTGTT & 2016-2036 & \\
\hline NORP3127F & CTITGATYACCACCACTCATGT & $3127-3150$ & $1191 \mathrm{bp}$ \\
\hline NORP4318R & TCTGTTGGGTGGAGTCCCA & 4299-4318 & \\
\hline NORP3819F & GAAACCATAGTGAATTITCTAG & $3819-3841$ & $540 \mathrm{bp}$ \\
\hline NORP4359R & CAGCAGAGAATTTCACCATG & 4339-4359 & \\
\hline NORP4051F & TGAARGATGARCTTGTSAAGAC & $4051-4073$ & $1087 \mathrm{bp}$ \\
\hline NORP5138R & TTGACCTCTGGTACGAGACC & $5118-5138$ & \\
\hline NVG4F & TGGATGCGRTTCTCNGACYT & $5007-5027$ & $1821 \mathrm{bp}$ \\
\hline NORP5647F & CGAACAATGCTGGGGATGATGTIT & $5647-5671$ & \\
\hline NORP6828R & TGATTAAKKGCATTRGYACCAGCA & $6804-6828$ & \\
\hline NORP6579F & CACCACAGGTAGAGTGCTC & $6579-6598$ & $1071 \mathrm{bp}$ \\
\hline NORP7650R & TITITाGGAGATCAGGGAACAG & $7627-7650$ & \\
\hline
\end{tabular}



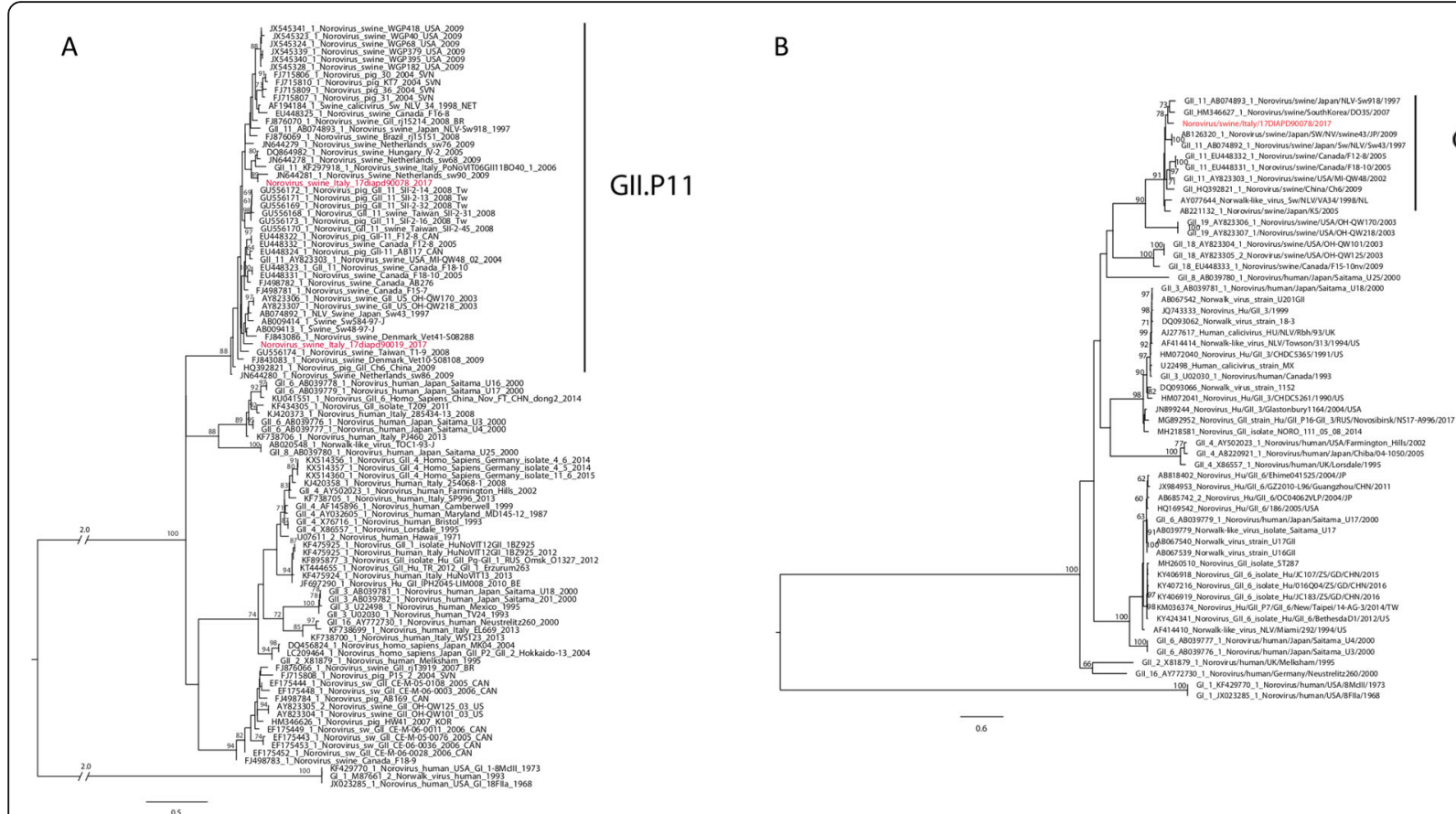

Fig. 1 a Phylogenetic tree of the RdRp nucleotide sequence on the left. Nucleotide substitution model: GTR + G; 100 bootstrap replicate. Only bootstrap values equal or higher than 60 are showed. In red the viruses identified in the present study. $\mathbf{b}$ Phylogenetic tree of the VP1 nucleotide sequence on the right. Nucleotide substitution model: GTR $+\mathrm{G}+$ l; 100 bootstrap replicate. Only bootstrap values equal or higher than 60 are showed. In red the virus identified in the present study

2017) from Verona province. No NoV positive faecal samples were detected in FVG region.

The phylogenetic analysis based on $300 \mathrm{bp}$ of the RdRp highlighted that the two Italian NoVs belong to the GII.P11 p-type but cluster into two different GII.P11 subgroups (Fig. 1a). The genetic similarity between 90078/2017 (accession number: MN567957) and 90019/2017 (accession number: MN567956) was $85.31 \%$. The $90078 / 2017$ NoV showed the highest nt similarity (91.70\%) with Norovirus/Swine/ Netherlands/sw90/2009 (JN644281), while 90019/2017 strain showed the highest similarity (89.74\%) with Nov/Swine/ Sw48-97-J (AB009413), suggesting that the two Italian samples were different from each other and from any other GII.P11 NoVs. At amino acid (aa) level the RdRp sequence of 90078/2017 NoV showed the highest similarity (98.9\%) with Nov/Swine/Sw48-97-J, while the RdRp sequence of the 90019/2017 NoV was identical to the RdRp of several NoVs.

Based on the phylogenetic analysis of the VP1 strain 90078/ 2017 belongs to the GII.11 genotype, as it clusters with NoVs identified in Japan in 1997 and in South Korea in 2007 (Fig. 1b). It was not possible to obtain the VP1 sequence of strain 90019/2017. The genetic distance computed on the nt sequence of VP1 showed that the sequence of strain 90078/ 2017 was significantly different from those available in Genbank, showing the highest nt similarity with GII.11 Norovirus/swine/Japan/NLV-Sw918/1997 (AB074893) (88.97\%) and the aa highest similarity (97.06\%) with GII.11 Sw/NLV/
VA34/1998/NL (AY077644). The comparison between 90078/2017 and the other GII.11 VP1 sequences available allowed the identification of six unique aa mutations (T224I, I290V, S336A, F370Y, R393K, T474A, aa positions in respect to Norovirus/swine/China/Ch6/2009).

The nearly complete genome sequence was obtained only for 90078/2017 and it was 7045 nt in length, with 18 and 500 nt missing toward the $5^{\prime}$ and the $3^{\prime}$ ends respectively, and organized in three open reading frames (ORFs). ORF1 showed the conserved cleavage sites and aa motifs typical of NoVs, including GRPGIGKT (nucleoside-triphosphatase (NTPase)), EYDEY (viral protein genome-linked (VPg)), GDCG (protease), and DYSRWDST, GLPSG and YGDD (RdRp). In accordance with the genome organization of other NoVs, ORF1 and ORF2 showed an overlap of twelve nt, with the latter encoding for the capsid protein in a +1 frame.

Recombination analysis showed the presence of a possible recombination event in the ORF1 with GII.P18 strain NoV/ swine/GII.18/OH-QW125/03/US (AY823305.2). The recombination event was supported $(p<0.05)$ by seven out of eight methods with PhylPro being the exception (Fig. 2); however, the presence of double peaks in the chromatograms in the area surrounding the potential break point (1847 (G/C), 1852 (C/A), 1858 (A/G), $1863(\mathrm{~T} / \mathrm{C})$ and $1875(\mathrm{~T} / \mathrm{C}))$, hinders its confident identification. Sequencing of the genomic region of interest was repeated using freshly isolated RNA and adopting different primer combinations. However, it was not possible 

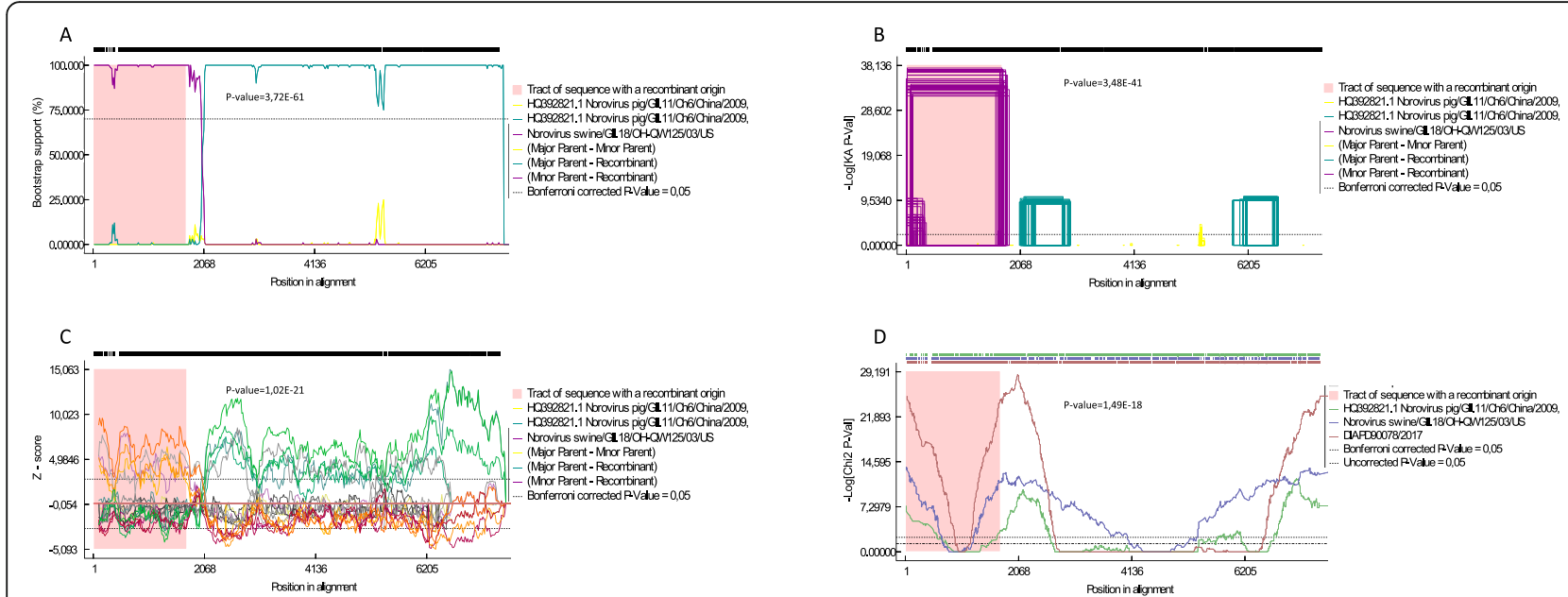

Fig. 2 RDP4 plots obtained with (a) BOOTSCAN, (b) GENECONV, (c) SISCAN and (d) CHIMAERA methods. The left and right bounds of the pink region indicate breakpoints suggested by the method. For easiness of representation, only four out of eight RPD4 plots are reported

to obtain any sequence deprived of double peaks around the putative break point.

Up to date, the only detection of $\mathrm{NoV}$ in swine reported in Italy resulted from a retrospective analysis on archived faecal samples collected in 2006, which did not disclose sample characteristics, source and geographic origin and produced merely a $300 \mathrm{bp}$ of the RdRp swine NoV sequence [17]. A follow-up study attempting to identify NoVs in swine in Italy proved unsuccessful [18]. Our investigation adds new and updated information on swine NoVs in Italy, obtained through sampling at the slaughterhouses. Although slaughterhouse sampling does have its limits, as primarily older animals are surveyed, it also presents several advantages in terms of animals and farms that can be potentially sampled, time and resources necessary, appearing a cost-effective approach to investigate the presence of NoVs for which epidemiological background information are missing in Italy.

NoV positivity $(2.53 \%)$ was in accordance with the previous reports on the detection of NoV in swine in Europe $[19,20]$; however, higher positivity rates were observed in studies conducted in Asia (>10\%) and North America (> 20\%) [21-23].

Based on the partial RdRp sequence, the Italian strains belong to the GII.P11 p-type, proving, however, to be genetically distinct from GII.P11 NoVs reported worldwide. The two strains, sampled only few months apart from animals originating from different provinces, showed a low RdRp genetic identity (85.31\%) between each other. This is suggestive of a high genetic variability among GII.P11 NoVs circulating in the area. This evidence, combined with the previous findings, which report that other age and production categories can harbour NoVs $[19,20,23,24]$, suggests that modifying the sampling strategy may have a remarkable impact on the number and type of NoVs detected in swine in Italy, possibly elucidating the association between NoV detection, animal categories and farm typology.

We reported the first European swine NoV nearly full genome sequence, obtained using an in-house primerwalking strategy. Full genome analysis revealed the presence of a possible recombination event in the ORF1. This process normally occurs in the ORF1/ORF2 overlap region [25], although recombination events in other genomic regions have also been reported [26]. The putative minor parental strain was identified as a virus belonging to the GII.P18/GII.18 genotype. Recombination events between NoV genotypes had been observed and represent a major threat for human and veterinary health, as novel recombinants might have different antigenic properties compared to their parental strains [27, 28]. However, our findings are not conclusive, as it was not possible to identify the recombination break point. Coinfections of NoVs belonging to different genotypes have been observed [25], hence the authors cannot exclude to be in the presence of a co-infection, rather than of a recombinant virus. The detection of GII.P18 genomic sequences suggests the circulation of this p-type in the area, making future investigations worthwhile.

NoV is largely studied as a human virus, only recently receiving attention for its capability of infecting terrestrial animals. Studies on NoV in swine remain isolated efforts, meaning that available information is disconnected by spatial-temporal gaps. Enhanced surveillance is uttermost necessary to explain the evolution and ecology of swine NoVs.

\section{Abbreviations}

Aa: Amino acid; FVG: Friuli Venezia Giulia; NoV: Norovirus; nt: Nucleotide; NTPase: Nucleoside-triphosphatase; ORF: Open reading frame;

PBS: Phosphate Buffered Saline; RdRp: RNA-dependent-RNA-polymerase; v/ 
V: Volume/volume; VP1: Major capsid protein; VPg: Viral protein genomelinked; w/v: Weight/volume

\section{Acknowledgments}

We thank Mrs. Francesca Ellero for the English revision and Dr. Lebana Bonfanti for her invaluable scientific support.

\section{Authors' contributions}

$M S B, A L, L C, L T$ conceived the project, analyzed the data and wrote the original draft of the manuscript; MSB conceptualized the project and acquired the funding; $A L, L C, L T, G C, A M, M U$ and $M C$ acquired the data; IM, MSB, MF and GDM supervised the project. The author(s) read and approved the final manuscript.

\section{Funding}

the Italian Ministry of Health supported the study financially ("Norovirus: towards a better understanding of its circulation in North East Italy - IZSVe 12/15 RC - Grant code: B22F16000270001).

\section{Availability of data and materials}

Data requests should be directed to the corresponding author.

\section{Ethics approval}

This article does not contain any studies with human participants or animals performed by any of the authors.

\section{Consent for publication}

All authors gave their consent for publication.

\section{Competing interests}

The authors declare that they have no competing interests.

\section{Author details}

${ }^{1}$ Research and Development Laboratory, Istituto Zooprofilattico Sperimentale Delle Venezie, Legnaro, Padua, Italy. ${ }^{2}$ Department of Comparative Biomedicine and Food Science, University of Padua, Legnaro, Padua, Italy. ${ }^{3}$ Diagnostic Virology Laboratory, Department of Animal Health, Istituto Zooprofilattico Sperimentale Delle Venezie, Legnaro, Padua, Italy. ${ }^{4}$ Epidemiology Department, Istituto Zooprofilattico Sperimentale Delle Venezie, Legnaro, Padua, Italy. ${ }^{5}$ Diagnostic Laboratory, Istituto Zooprofilattico Sperimentale Delle Venezie, Via Bassa del Cuc 4, 33084, Cordenons, Pordenone, Italy. ${ }^{6}$ Department of Veterinary Science, University of Pisa, Viale delle Piagge 2, 56124 Pisa, Italy.

\section{Received: 20 December 2019 Accepted: 4 March 2020}

\section{Published online: 16 April 2020}

\section{References}

1. Verhoef L, Kouyos RD, Vennema H, Kroneman A, Siebenga J, van Pelt W, et al. An integrated approach to identifying international foodborne norovirus outbreaks. Emerg Infect Dis. 2011;17(3):412-8. https://doi.org/10. 3201/eid1703.100979.

2. Belliot G, Lopman BA, Ambert-Balay K, Pothier P. The burden of norovirus gastroenteritis: an important foodborne and healthcare-related infection. Clin Microbiol Infect. 2014;20(8):724-30. https://doi.org/10.1111/1469-0691. 12722.

3. de Graaf M, van Beek J, Koopmans MPG. Human norovirus transmission and evolution in a changing world. Nat Rev Microbiol. 2016;14(7):421-33. https://doi.org/10.1038/nrmicro.2016.48.

4. Chhabra P, de Graaf M, Parra Gl, Chan MC, Green K, Martella V, et al. Updated classification of norovirus genogroups and genotypes. J Gen Virol. 2019;100(10):1393-406. https://doi.org/10.1099/jgv.0.001318.

5. Cunha JB, de Mendonça MCL, Miagostovich MP, Leite JPG. First detection of porcine norovirus Gll.18 in Latin America. Res Vet Sci. 2010;89(1):126-9. https://doi.org/10.1016/..rvsc.2009.

6. Shen Q, Zhang W, Yang S, Cui L, Hua X. Complete genome sequence of a new-genotype porcine norovirus isolated from piglets with diarrhea. J Virol. 2012;86(12):7015-6. https://doi.org/10.1128/JVI.00757-12.

7. Reuter G, Bíró H, Szűcs G. Enteric caliciviruses in domestic pigs in Hungary. Arch Virol. 2007;152(3):611-4. https://doi.org/10.1007/s00705-006-0887-8.
8. Shen Q, Zhang W, Yang S, Chen Y, Ning H, Shan T, et al. Molecular detection and prevalence of porcine caliciviruses in eastern China from 2008 to 2009. Arch Virol. 2009;154(10):1625-30. https://doi.org/10.1007/ s00705-009-0487-5.

9. Silva PF, Alfieri AF, Barry AF, de Arruda Leme R, Gardinali NR, van der Poel $\mathrm{WH}$, et al. High frequency of porcine norovirus infection in finisher units of Brazilian pig-production systems. Trop Anim Health Prod. 2015;47(1):237-41. https://doi.org/10.1007/s11250-014-0685-3.

10. Wang Q, Han MG, Cheetham S, Souza M, Funk JA, Saif LJ. Porcine Noroviruses related to human Noroviruses. Emerg Infect Dis. 2005;11(12): 1874-81. https://doi.org/10.3201/eid1112.050485.

11. Villabruna N, Koopmans MPG, de Graaf M. Animals as reservoir for human Norovirus. Viruses. 2019;11(5). https://doi.org/10.3390/v11050478.

12. Bondoc I. European regulation in the veterinary sanitary and food safety area, a component of the european policies on the safety of food products and the protection of consumer interests: a 2007 retrospective. Part one: the role of european institutions in laying down and passing laws specific to the veterinary sanitary and food safety area. 2016; Revista universul juridic, Supliment 12-15. http://revista.universuljuridic.ro/supliment/europeanregulation-veterinary-sanitary-food-safety-area-component-european-policiessafety-food-products-protection-consumer-interests-2007-retrospective/.

13. Bondoc I. European regulation in the veterinary sanitary and food safety area, a component of the european policies on the safety of food products and the protection of consumer interests: a 2007 retrospective. Part two: regulations. 2016; Revista universul juridic, Supliment 16-19. http://revista. universuljuridic.ro/supliment/european-regulation-veterinary-sanitary-foodsafety-area-component-european-policies-safety-food-products-protectionconsumer-interests-2007-retrospective-2.

14. Bondoc I. European regulation in the veterinary sanitary and food safety area, component of european policies on the safety of food products and the protection of consumer interests: a 2007 retrospective. Part three: directives. 2016; Revista universul juridic, Supliment 20-23. http://revista. universuljuridic.ro/supliment/european-regulation-veterinary-sanitary-foodsafety-area-component-european-policies-safety-food-products-protectionconsumer-interests-2007-retrospective-part/.

15. Bondoc I. European regulation in the veterinary sanitary and food safety area, component of european policies on the safety of food products and the protection of consumer interests: a 2007 retrospective. Part four: decisions. 2016; Revista universul juridic, Supliment 24-27. http://revista. universuljuridic.ro/supliment/european-regulation-veterinary-sanitary-foodsafety-area-component-european-policies-safety-food-products-protectionconsumer-interests-2007-retrospective-part-2/.

16. Jiang X, Huang PW, Zhong WM, Farkas T, Cubitt DW, Matson DO. Design and evaluation of a primer pair that detects both Norwalk- and Sapporo-like caliciviruses by RT-PCR. J Virol Methods. 1999:83(1-2):145-54. https://doi. org/10.1016/s0166-0934(99)00114-7.

17. Di Bartolo I, Tofani S, Angeloni G, Ponterio E, Ostanello F, Ruggeri F. Detection and characterization of porcine caliciviruses in Italy. Arch Virol. 2014;159(9):2479-84. https://doi.org/10.1007/s00705-014-2076-5.

18. Monini M, Di Bartolo I, laniro G, Angeloni G, Magistrali C, Ostanello F, et al. Detection and molecular characterization of zoonotic viruses in swine fecal samples in Italian pig herds. Arch Virol. 2015;160(10):2547-56. https://doi. org/10.1007/s00705-015-2538-4.

19. Mauroy A, Scipioni A, Mathijs E, Miry C, Ziant D, Thys C, et al. Noroviruses and sapoviruses in pigs in Belgium. Arch Virol. 2008;153(10):1927-31. https:// doi.org/10.1007/s00705-008-0189-4.

20. Mijovski JZ, Poljšak-Prijatelj M, Steyer A, Barlič-Maganja D, Koren S. Detection and molecular characterisation of noroviruses and sapoviruses in asymptomatic swine and cattle in Slovenian farms. Infect Genet Evol. 2010; 10(3):413-20. https://doi.org/10.1016/j.meegid.2009.11.010.

21. Scheuer KA, Oka T, Hoet AE, Gebreyes WA, Molla BZ, Saif LJ, et al. Prevalence of porcine noroviruses, molecular characterization of emerging porcine sapoviruses from finisher Swine in the United States, and unified classification scheme for sapoviruses. J Clin Microbiol. 2013;51(7):2344-53. https://doi.org/10.1128/JCM.00865-13.

22. Nakamura K, Saga Y, Iwai M, Obara M, Horimoto E, Hasegawa S, et al. Frequent detection of noroviruses and sapoviruses in Swine and high genetic diversity of porcine sapovirus in Japan during fiscal year 2008. J Clin Microbiol. 2010;48(4):1215-22. https://doi.org/10.1128/JCM.02130-09.

23. Wang QH, Souza M, Funk JA, Zhang W, Saif L. Prevalence of noroviruses and sapoviruses in Swine of various ages determined by reverse 
transcription-PCR and microwell hybridization assays. J Clin Microbiol. 2006; 44(6):2057-62. https://doi.org/10.1128/JCM.02634-05.

24. Shen $\mathrm{Q}$, Zhang W, Yang S, Yang Z, Chen Y, Cui L, et al. Recombinant porcine norovirus identified from piglet with diarrhea. BMC Veterinary Res. 2012;8(1):155. https://doi.org/10.1186/1746-6148-8-155.

25. Bull RA, Tanaka MM, White PA. Norovirus recombination. J Gen Virol. 2007; 88(12):3347-59. https://doi.org/10.1099/vir.0.83321-0.

26. Motomura K, Yokoyama M, Ode H, Nakamura H, Mori H, Kanda T, et al. Divergent evolution of norovirus GII/4 by genome recombination from may 2006 to February 2009 in Japan. J Virol. 2010;84(16):8085-97. https://doi.org/ 10.1128/JVI.02125-09.

27. Eden J, Tanaka M, Boni MF, Rawlinson WD, White PA. Recombination within the pandemic norovirus Gll.4 lineage. J Virol. 2013;87(11):6270-82. https:// doi.org/10.1128/JVI.03464-12.

28. Lam TT, Zhu H, Smith DK, Guan Y, Holmes EC, Pybus OG. The recombinant origin of emerging human norovirus Gll.4/2008: intra-genotypic exchange of the capsid P2 domain. J Gen Virol. 2012;93(Pt 4):817-22. https://doi.org/ 10.1099/vir.0.039057-0.

\section{Publisher's Note}

Springer Nature remains neutral with regard to jurisdictional claims in published maps and institutional affiliations.

Ready to submit your research? Choose BMC and benefit from:

- fast, convenient online submission

- thorough peer review by experienced researchers in your field

- rapid publication on acceptance

- support for research data, including large and complex data types

- gold Open Access which fosters wider collaboration and increased citations

- maximum visibility for your research: over $100 \mathrm{M}$ website views per year

At BMC, research is always in progress.

Learn more biomedcentral.com/submissions 